\title{
Follicular populations and luteal function in dairy heifers treated with a controlled internal drug release insert for 14 days as a method to synchronize the estrous cycle before prostaglandin $F_{2 \alpha}$ treatment and artificial insemination
}

\author{
R. C. Escalante, S. E. Poock, and M. C. Lucy ${ }^{1}$ \\ Division of Animal Sciences and College of Veterinary Medicine, University of Missouri, Columbia 65211
}

\begin{abstract}
Progesterone-containing controlled internal drug release (CIDR) inserts are used to synchronize the estrous cycle before $\mathrm{PGF}_{2 \alpha}$ is administered for timed AI (14dCIDR-PGF ${ }_{2 \alpha}$ program). The program, initially designed for beef cattle, was recently shown to be efficacious in dairy heifers. We hypothesized that the 14-d CIDR treatment would synchronize the estrous cycle in dairy heifers and result in a uniformly sized corpus luteum (CL) and largest follicle (LF) at the time of $\mathrm{PGF}_{2 \alpha}$ treatment. Holstein $(\mathrm{n}=110)$ or Holstein $\times$ Guernsey $(\mathrm{n}=4)$ dairy heifers were assigned to 2 treatments: (1) $14 \mathrm{dCIDR}^{-P G F_{2 \alpha}}$ [CIDR in for $14 \mathrm{~d}$, CIDR out for $16 \mathrm{~d}, \mathrm{PGF}_{2 \alpha}$ and $\mathrm{AI}$ after observed estrus $(\mathrm{n}=57)]$ or $(2)$ control $\left[\mathrm{PGF}_{2 \alpha}\right.$ and AI after observed estrus $(\mathrm{n}=57)]$. Regardless of treatment, additional $\mathrm{PGF}_{2 \alpha}$ injections were administered at 14-d intervals to heifers that were not seen in estrus. Ovarian ultrasonography and blood sampling were done on $\mathrm{d} 0$ (CIDR administered), 14 (day CIDR removed), 19 (5 d after CIDR removed), 30 ( $\mathrm{PGF}_{2 \alpha}$ administered), and 44 (second $\mathrm{PGF}_{2 \alpha}$ dose administered to heifers that were not detected in estrus after the first $\left.\mathrm{PGF}_{2 \alpha}\right)$. Compared with control (untreated), more CIDR-treated heifers were categorized as having a small CL $(\leq 9.9 \mathrm{~mm})$ and large LF (15.0-19.9 mm) on d 14 (CIDR removal) and, as expected, a greater percentage of CIDR-treated heifers were in estrus during the $5 \mathrm{~d}$ after the CIDR removal compared with control heifers (75.4 vs. $22.8 \%$, respectively). On d 19, the CIDR-treated heifers had apparently ovulated based on disappearance of LF and appearance of small CL. On d $30\left(\mathrm{PGF}_{2 \alpha}\right.$ administration), $89 \%$ of $14 \mathrm{dCIDR}^{-\mathrm{PGF}_{2 \alpha}}$ heifers had CL that were $\geq 20 \mathrm{~mm}$ in diameter compared with $55 \%$ for control. Presence of larger CL on d 30 was associated with greater concentrations of plasma progesterone in
\end{abstract}

Received December 12, 2012.

Accepted February 25, 2013.

${ }^{1}$ Corresponding author: lucym@missouri.edu
14dCIDR-PGF ${ }_{2 \alpha}$ compared with control $(10.5 \pm 0.5$ vs. $5.0 \pm 0.6 \mathrm{ng} / \mathrm{mL}$, respectively). The percentages of heifers with LF in the smallest category $(\leq 9.9 \mathrm{~mm})$ tended to be less (5.3 vs. $16.6 \%$ ) and the percentage of heifers with LF in the medium-size category (10.0 to $14.9 \mathrm{~mm}$ ) tended to be greater ( 84.2 vs. $69.1 \%$ ) for $14 \mathrm{dCIDR}-\mathrm{PGF}_{2 \alpha}$ versus control, respectively, on d 30 . More heifers were detected in estrus within $5 \mathrm{~d}$ after the first $\mathrm{PGF}_{2 \alpha}(86.0$ vs. $56.1 \%)$ and conception rate to AI using sexed semen tended to be greater $(61.2 \%$ vs. $40.6 \%$ ) for $14 \mathrm{dCIDR}-\mathrm{PGF}_{2 \alpha}$ compared with control (respectively). Treating dairy heifers with a CIDR for $14 \mathrm{~d}$ was an effective method to synchronize an estrous cycle before $\mathrm{PGF}_{2 \alpha}$ was administered.

Key words: controlled internal drug release, prostaglandin $\mathrm{F}_{2 \alpha}$, artificial insemination, heifer

\section{INTRODUCTION}

The original method to control the estrous cycle in dairy or beef cattle was by feeding or administering progestogens (e.g., melengestrol acetate, medroxyprogesterone acetate, or progesterone; Patterson et al., 1989; Odde, 1990; Lauderdale, 2009). The estrous cycle is controlled by progestogens because progestogens suppress estrus and inhibit ovulation. Estrous cycles can be synchronized by removing progestogens from a group of cattle and relieving the block to estrus and ovulation in a synchronous manner. In addition to synchronizing estrus, progestogens have the additional advantage of inducing cyclicity in cattle that are not cycling at the start of treatment (Anderson et al., 1996; Lucy et al., 2001). Feeding or treating cattle with progestogens for 2 to $3 \mathrm{wk}$ will synchronize estrus, but the fertility of the first estrus after the long-term progestogen treatment is poor (Patterson et al., 1989). The poor fertility is caused by detrimental effects on the oocyte that resides within the long-lived (persistent) dominant follicle that develops during progestogen treatment (Ahmad et al., 1995; Revah and Butler, 1996; Roche et al., 1999). Although the oocyte is damaged, the persistent dominant 
follicle can ovulate and form a functional corpus luteum (CL). Progestogens can be used, therefore, to synchronize the development of a CL during an estrous cycle. Regression of the CL is then initiated at an appropriate time by using a luteolyic dose of $\mathrm{PGF}_{2 \alpha}$. The CL regression is followed by a fertile estrus. Leitman et al. (2009) found that a controlled internal drug release (CIDR) insert containing progesterone (Pfizer Animal Health, New York, NY), inserted for $14 \mathrm{~d}$ in beef heifers, effectively synchronized ovulation and CL formation so that $\mathrm{PGF}_{2 \alpha}$ could be administered $16 \mathrm{~d}$ after insert removal to synchronize estrus before AI.

Most reproductive programs for dairy heifers use a luteolytic dose of $\mathrm{PGF}_{2 \alpha}$ to synchronize estrus (Louis et al., 1973; Lauderdale, 2009). A recently formed CL (less than 5-d-old) will not generally regress in response to $\mathrm{PGF}_{2 \alpha}$. To overcome this limitation, 2 injections of $\mathrm{PGF}_{2 \alpha}$ are administered 11 to $14 \mathrm{~d}$ apart. The combination of the 2 injections leads to a large percentage of heifers in estrus after the second injection. In practice, dairy heifers are inseminated after estrus following the first $\mathrm{PGF}_{2 \alpha}$ injection (presumably these heifers had a $\mathrm{PGF}_{2 \alpha}$-responsive CL that was at least 5-d-old), and those heifers not observed in estrus are given a second $\mathrm{PGF}_{2 \alpha}$ injection 11 to $14 \mathrm{~d}$ later. An alternative method to the $\mathrm{PGF}_{2 \alpha}$-alone system is to create a large percentage of heifers with a CL at the time of the first $\mathrm{PGF}_{2 \alpha}$ injection. This can be accomplished by treating with progesterone (via CIDR) for $14 \mathrm{~d}$ and then treating with $\mathrm{PGF}_{2 \alpha} 16 \mathrm{~d}$ after CIDR insert removal, as reported by Leitman et al. (2009) in beef heifers and recently tested and shown to be effective in dairy heifers for timed AI (Mallory et al., 2013).

We hypothesized that the 14-d progesterone exposure via CIDR insert treatment would be an effective method to synchronize the estrous cycle and achieve a uniform CL and dominant follicle before $\mathrm{PGF}_{2 \alpha}$ treatment and AI in dairy heifers. The objective was to examine the CL, follicular populations, and progesterone in dairy heifers that were either treated for $14 \mathrm{~d}$ with progesterone (CIDR) or left untreated (control) before a luteolytic dose of $\mathrm{PGF}_{2 \alpha}$ intended to synchronize estrus before AI. Ovaries were examined by transrectal ultrasound to assess the response to treatment. Interval to estrus and fertility after $\mathrm{PGF}_{2 \alpha}$ and $\mathrm{AI}$ were also measured.

\section{MATERIALS AND METHODS}

The Institutional Animal Care and Use Committee of the University of Missouri approved the use of animals before the start of the trial (Protocol number 6814 entitled, "Show-me synch estrous synchronization in dairy cows and dairy heifers").

\section{Animals}

Dairy heifers $(\mathrm{n}=114)$ at the University of Missouri Foremost dairy (Midway, Missouri) were enrolled. The trial was conducted during 2 different years [year 1 (n $=40)=$ December 2010 to May 2011; year $2(\mathrm{n}=74)$ $=$ December 2011 to May 2012]. Heifers were either Holstein $(\mathrm{n}=110)$ or Holstein $\times$ Guernsey $(\mathrm{n}=4)$. All heifers between 12 and 17 mo of age were weighed and their height at the withers was measured at the start of the trial. Heifers were kept in sheltered freestalls on a concrete dry lot. Fresh water and brome hay (round bale feeder) were accessible at all times. Heifers were fed a TMR once daily that contained corn silage, alfalfa haylage, alfalfa hay, corn grain, soybean grain, soybean hulls, wet brewers grains, and trace vitamin and mineral premix. The TMR was balanced to meet nutritional requirements according to the National Research Council (2001).

\section{Synchronization and Al}

Heifers were assigned randomly to a treatment and a control (Figure 1). The treatment group (14dCIDR$\mathbf{P G F}_{2 \alpha} ; \mathrm{n}=57$ ) were administered a CIDR insert (Eazi-Breed CIDR Cattle insert containing $1.38 \mathrm{~g}$ of progesterone; Pfizer Animal Health) on d 0 for $14 \mathrm{~d}$. At $16 \mathrm{~d}$ after CIDR removal (d 30), heifers were treated with $\mathrm{PGF}_{2 \alpha}$ (5 mL LUTALYSE Sterile Solution, i.m.; $25 \mathrm{mg}$ dinoprost; Pfizer Animal Health). Control heifers did not receive a CIDR and were administered $\mathrm{PGF}_{2 \alpha}$ at the same time as the $14 \mathrm{dCIDR}-\mathrm{PGF}_{2 \alpha}$ heifers (d 30). Observations for estrus were made twice daily during the first $5 \mathrm{~d}$ after $\mathrm{PGF}_{2 \alpha}$ administration by using visual observation and by examining Estrotect Alert Patches (Estrotect Inc., Spring Valley, WI) for indication of estrus. Sexed semen was used for AI that was conducted according to the a.m.-p.m. rule (heifers observed in estrus in the morning received AI in the afternoon; heifers observed in estrus in the afternoon received AI the following morning). Two technicians performed all inseminations and each inseminator worked both years. Twenty-five different bulls were used for AI. Regardless of treatment, heifers that were not observed in estrus after the first $\mathrm{PGF}_{2 \alpha}$ injection received a second $\mathrm{PGF}_{2 \alpha}$ injection on $\mathrm{d} 44$ (14 d after the first injection) and those observed in estrus were inseminated with sexed semen according to the a.m.-p.m. rule. Heifers from either treatment not identified in estrus to either of the first $2 \mathrm{PGF}_{2 \alpha}$ injections were administered a third injection of $\mathrm{PGF}_{2 \alpha}$ on $\mathrm{d} 58$ ( $14 \mathrm{~d}$ after the second injection) and upon observed estrus received AI with sexed semen according to the a.m.-p.m. rule. 


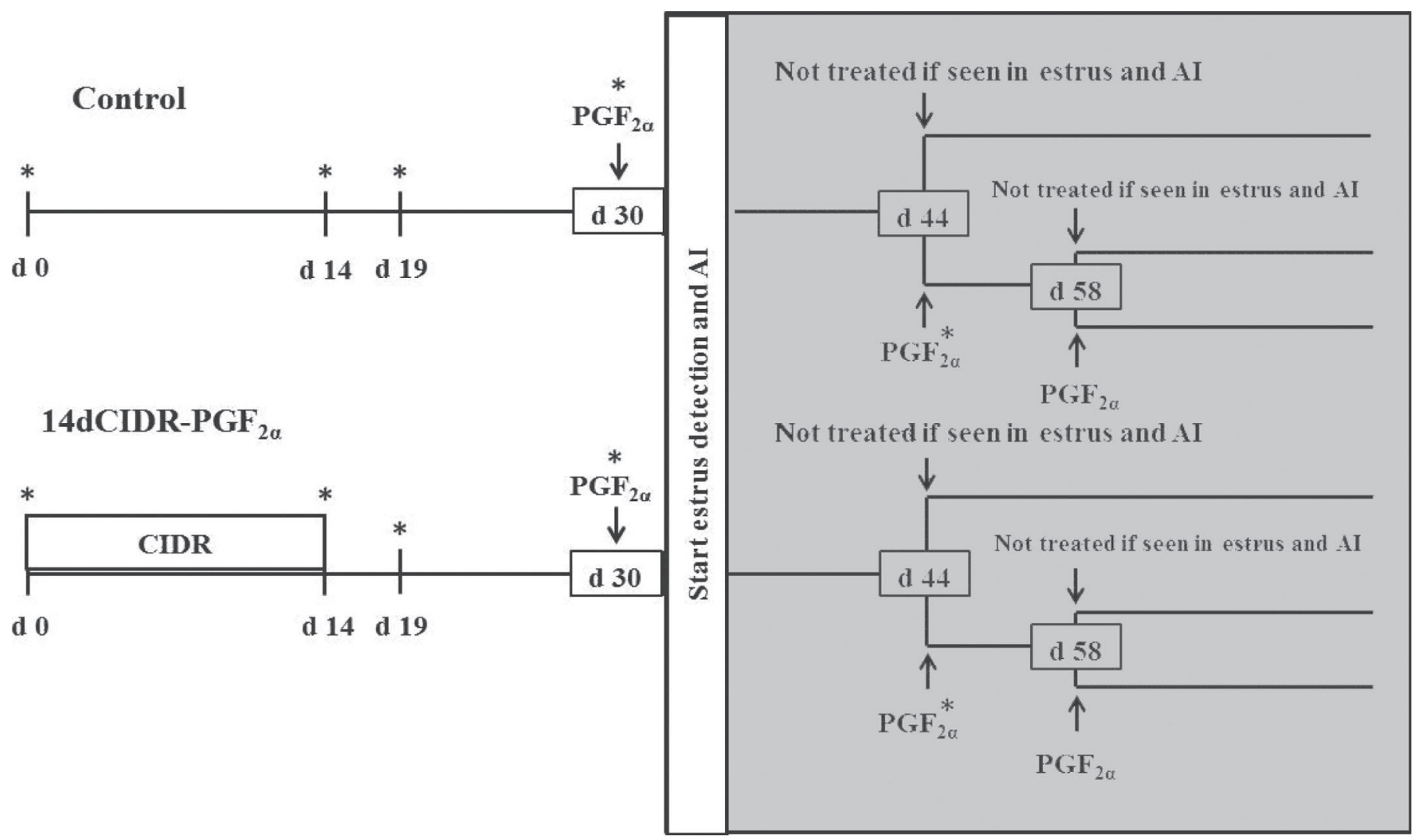

Figure 1. Timeline for treatment administration for heifers treated with a controlled internal drug release (CIDR) of progesterone for $14 \mathrm{~d}$ (14dCIDR-PGF ${ }_{2 \alpha} ; 1.38 \mathrm{~g}$ of progesterone; Pfizer Animal Health, New York, NY) or a control program. PGF ${ }_{2 \alpha}=5 \mathrm{~mL}$ Lutalyse Sterile Solution, i.m. (25 mg of dinoprost; Pfizer Animal Health). An asterisk indicates blood sample collection and examination of ovaries by transrectal ultrasound.

\section{Ultrasound and Blood Samples}

The ovaries of heifers were examined by using transrectal ultrasound (Aloka 500V equipped with a 7.5$\mathrm{MHz}$ linear transducer; Aloka, Wallingford, CT) on d 0 (CIDR administered), 14 (CIDR removed), 19 (5 d after CIDR removed), 30 ( $\mathrm{PGF}_{2 \alpha}$ administered), and 44 (second $\mathrm{PGF}_{2 \alpha}$ dose administered to heifers that were not detected as being in estrus after the first $\mathrm{PGF}_{2 \alpha}$ ). A blood sample was collected from the median caudal vein or artery into a vacutainer tube containing EDTA (Tyco Healthcare Group, Mansfield, MA) before each ultrasound examination. Blood was immediately placed on ice after collection. The samples were processed within $4 \mathrm{~h}$ after collection by centrifuging for $15 \mathrm{~min}$ at $1,500 \times g$, collecting the plasma, and storing the plasma at $-20^{\circ} \mathrm{C}$. Plasma progesterone concentrations were analyzed by using a radioimmunoassay (Coat-ACount Progesterone, Siemens Health Care Diagnostics Inc., Los Angeles, CA), which was validated in our laboratory for use with bovine plasma samples (Kirby et al., 1997). The intra- and interassay CV for the progesterone assays were 6.5 and $7.1 \%$, respectively.
Pregnancy diagnosis was performed by veterinarians from the University of Missouri College of Veterinary Medicine 35 to $42 \mathrm{~d}$ after AI by using transrectal ultrasound examination. A second ultrasound examination was done 56 to $63 \mathrm{~d}$ after AI to confirm pregnancy.

\section{Statistical Analyses}

Age, BW, and Height. The age, BW, and height of the heifers were tested for an effect of assignment to treatment by using PROC GLM of SAS (SAS Institute Inc., Cary, NC).

Ovarian Follicles and $\boldsymbol{C L}$. Diameters of the CL, largest ovarian follicle (LF), second largest ovarian follicle (SLF), number of class 1 (2-5 $\mathrm{mm}$ diameter), class 2 (6-9 $\mathrm{mm}$ diameter), and class 3 ( $\geq 10 \mathrm{~mm}$ diameter) follicles, and the concentration of progesterone in plasma were initially analyzed for the effects of treatment (14dCIDR-PGF $\mathrm{PG}_{2 \alpha}$ and control), day (0, 14,19 , and 30), and the interaction of treatment by day. The analyses were conducted using a mixed models procedure (PROC MIXED, SAS Institute Inc.); 
the heterogeneous compound symmetry structure was used. Heifer nested within treatment was included in the model as a random effect; day was included in the model as a repeated variable. The same data (diameter of CL, LF, and SLF, number of class 1, 2, and 3 follicles, and plasma progesterone) also were analyzed for each individual day by using PROC GLM and a model that included treatment. In addition to the abovementioned analyses, both CL and LF were categorized based on diameter, where category (CAT) $1=\leq 9.9 \mathrm{~mm}$, CAT $2=10.0$ to $14.9 \mathrm{~mm}$, CAT $3=15.0$ to $19.9 \mathrm{~mm}$ and CAT $4=\geq 20 \mathrm{~mm}$. The effect of treatment on the percentage of heifers possessing CL or LF within the individual categories on each day was tested by using the Chi-squared function within PROC FREQ (SAS Institute Inc.; 2 treatments $\times 4$ category contingency table). Within day, the percentage of heifers within a specific category was also tested by using a Fisher's exact test. Plasma progesterone concentrations in heifers were tested for the effects of treatment, CL category, day, and all interactions. The analyses were conducted by using a mixed models procedure (PROC MIXED). The heterogeneous compound symmetry structure was used. Heifer nested within treatment was included in the model as a random effect. Day was included in the model as a repeated variable.

Interval to Estrus. The effect of treatment on the interval to estrus $(0,1,2,3,4$, or $5 \mathrm{~d})$ or not detected in estrus after CIDR removal or after $\mathrm{PGF}_{2 \alpha}$ was tested using the Chi-squared function within PROC FREQ (2 treatments $\times 7$ category contingency table). The percentage of heifers in estrus on a specific day and the percentage of heifers not detected in estrus were also tested by using a Fisher's exact test. The actual interval to estrus (d) was tested by using PROC GLM.

Conception Rate. The first insemination conception rate (heifers inseminated after the first $\mathrm{PGF}_{2 \alpha}$ injection or any additional $\mathrm{PGF}_{2 \alpha}$ injection) and also second insemination conception rate were analyzed for the effect of treatment, AI technician, and treatment by AI technician. The GENMOD procedure (SAS Institute Inc.) was used for the statistical analysis.

Survival Analyses. The product-limit survival estimates of heifers that were not inseminated or were not pregnant on a given day after first $\mathrm{PGF}_{2 \alpha}$ for the individual treatments were tested by using the LIFETEST procedure (SAS Institute Inc.). The log-rank $P$-value for the LIFETEST procedure was used for the test of significance.

General. Means are reported as least squares means \pm SEM unless stated otherwise. Statistical significance was declared at $P \leq 0.05$. Statistical tendency was defined as $0.05<P \leq 0.10$.

\section{RESULTS}

\section{Heifer Age, BW, and Height}

Heifers assigned to each treatment were similar for age, BW, and height. The mean $\pm \mathrm{SD}$ across both treatments for age, BW, and height were $14.3 \pm 0.9$ mo, $342 \pm 29.3 \mathrm{~kg}$, and $133.3 \pm 4.9 \mathrm{~cm}$, respectively.

\section{Ovarian and Endocrine Response to Treatment}

Corpus Luteum and Progesterone. A treatment by day interaction was detected for diameter of the CL $(P<0.001)$ and plasma progesterone concentrations $(P<0.001)$. The diameter of the CL on $\mathrm{d} 0$ was not affected by treatment $(13.9 \pm 0.9 \mathrm{~mm})$. Subsequently, the diameter of the CL was lesser for $14 \mathrm{dCIDR}-\mathrm{PGF} \mathrm{F}_{2 \alpha}$ compared with control on d $14(6.4 \pm 1.2$ vs. $17.2 \pm$ $1.2 \mathrm{~mm})$ and $\mathrm{d} 19(8.1 \pm 1.1$ vs. $16.4 \pm 1.1 \mathrm{~mm})$, but greater on d $30(21.3 \pm 0.8$ vs. $18.1 \pm 0.8 \mathrm{~mm})$. Likewise, plasma progesterone concentrations were similar on d $0(4.7 \pm 0.4 \mathrm{ng} / \mathrm{mL})$ but were lesser for $14 \mathrm{dCIDR}$ $\mathrm{PGF}_{2 \alpha}$ compared with control on d 14 (3.3 \pm 0.5 vs. $5.6 \pm 0.5 \mathrm{ng} / \mathrm{mL})$ and $\mathrm{d} 19(1.1 \pm 0.4$ vs. $5.4 \pm 0.4 \mathrm{ng} /$ $\mathrm{mL}$ ), but greater for $14 \mathrm{dCIDR}^{-} \mathrm{PGF}_{2 \alpha}$ compared with control on d $30(10.5 \pm 0.5$ vs. $5.0 \pm 0.6 \mathrm{ng} / \mathrm{mL})$.

Heifers were placed into different categories based on diameter of the CL at the time of ultrasound examination. When all data were analyzed collectively (both treatments; d 0, 19, and 30; d 14 not included because the CIDR insert confounded results), the mean concentrations of plasma progesterone increased $(P<0.001)$ in heifers with increasing CL category; CAT $1(\leq 9.9$ $\mathrm{mm} ; 0.6 \pm 0.3 \mathrm{ng} / \mathrm{mL}$ ), CAT 2 (10.0 to $14.9 \mathrm{~mm} ; 1.0$ $\pm 0.4 \mathrm{ng} / \mathrm{mL}$ ), CAT 3 (15.0 to $19.9 \mathrm{~mm} ; 5.0 \pm 0.4 \mathrm{ng} /$ $\mathrm{mL})$, and CAT $4(\geq 20 \mathrm{~mm} ; 9.0 \pm 0.2 \mathrm{ng} / \mathrm{mL})$.

No effect of treatment was detected for the percentage of heifers in different CL categories on $\mathrm{d} 0$ (the majority of heifers had either a CAT 1 or a CAT 4 CL; Figure 2A) and no effect of treatment was detected for the concentration of plasma progesterone in heifers with different category CL on d 0 (Figure 2E). On d 14 (day of CIDR removal for $14 \mathrm{dCIDR}^{-} \mathrm{PGF}_{2 \alpha}$ heifers), an effect of treatment on percentage of heifers in each CL category was observed $(P<0.001)$. The effect was seen in a greater percentage of heifers with CAT $1 \mathrm{CL}(P$ $<0.001)$ and a lesser percentage of heifers with CAT 4 $\mathrm{CL}(P<0.001)$ in $14 \mathrm{dCIDR}^{-\mathrm{PGF}_{2 \alpha}}$ heifers compared with control on d 14 (Figure 2B). No effect of treatment on the concentrations of progesterone in heifers in different CL categories on d 14 was noted (Figure 2F). On d 19 ( $5 \mathrm{~d}$ after CIDR removal for 14dCIDR-PGF $2 \alpha$ heifers), the percentage of heifers in different CL categories differed $(P<0.001)$. The difference was greater 
in 14dCIDR-PGF ${ }_{2 \alpha}$ heifers with CAT $1(P<0.05)$ and CAT $2(P<0.01)$ CL and lesser in 14dCIDR-PGF $2 \alpha$ heifers with CAT 4 CL $(P<0.001)$ compared with control (Figure 2C). Plasma progesterone concentrations in $14 \mathrm{dCIDR}-\mathrm{PGF}_{2 \alpha}$ heifers that possessed CAT4 CL were lesser $(P<0.001)$ than control heifers with CAT 4 CL (Figure 2G; treatment by CL category, $P$ $<0.001$ ). On d 30 (day that $\mathrm{PGF}_{2 \alpha}$ was administered to all heifers) a greater percentage of $14 \mathrm{dCIDR}-\mathrm{PGF}_{2 \alpha}$ heifers with CAT 4 CL compared with control was noted (Figure 2D; $P<0.001$ ). Progesterone concentrations were greater for $14 \mathrm{dCIDR}-\mathrm{PGF}_{2 \alpha}$ heifers that possessed either CAT 3 or CAT 4 CL compared with control heifers that possessed CAT 3 or CAT 4 CL, respectively (Figure $2 \mathrm{H}$; treatment by CL category, $P<0.001$ ).

Ovarian Follicles. A treatment by day interaction was observed for diameter of the $\operatorname{LF}(P<0.001)$ and SLF $(P<0.001)$ and the number of class $2(P<0.05)$ and class $3(P<0.001)$ follicles. The treatment by day interaction was not significant for the number of class 1 follicles. The diameter of the LF $(11.9 \pm 0.3 \mathrm{~mm})$ and SLF $(7.7 \pm 0.2 \mathrm{~mm})$, and the number of class 2 $(1.6 \pm 0.2)$ and class $3(1.1 \pm 0.1)$ follicles on $\mathrm{d} 0$ were not different for heifers assigned to each treatment. Subsequently, the diameter of the LF was greater for $14 \mathrm{dCIDR}-\mathrm{PGF}_{2 \alpha}$ compared with control on d 14 (13.8 \pm 0.4 vs. $12.2 \pm 0.4 \mathrm{~mm}$ ); the LF was smaller for 14dCIDR-PGF 2 $_{2 \alpha}$ compared with control on d 19 (10.1 \pm 0.4 vs. $12.1 \pm 0.4 \mathrm{~mm}$ ); but the LF was similar in diameter for the $14 \mathrm{dCIDR}-\mathrm{PGF}_{2 \alpha}$ compared with control on $\mathrm{d} 30(12.8 \pm 0.4$ vs. $12.0 \pm 0.4 \mathrm{~mm})$. The SLF was similar in diameter for $14 \mathrm{dCIDR}-\mathrm{PGF}_{2 \alpha}$ and control on d $14(7.2 \pm 0.3 \mathrm{~mm})$; was smaller in diameter for 14dCIDR-PGF ${ }_{2 \alpha}$ compared with control on d 19 (7.3 \pm 0.3 vs. $8.4 \pm 0.3 \mathrm{~mm}$ ); and was greater in diameter for 14dCIDR-PGF ${ }_{2 \alpha}$ compared with control on d 30 (9.5 \pm 0.3 vs. $7.6 \pm 0.3 \mathrm{~mm})$. The class 3 follicles were greater in number in $14 \mathrm{dCIDR}-\mathrm{PGF}_{2 \alpha}$ compared with control on $\mathrm{d} 14(1.2 \pm 0.1$ vs. $1.0 \pm 0.1)$; fewer in 14dCIDR$\mathrm{PGF}_{2 \alpha}$ compared with control on d 19 (0.8 \pm 0.1 vs. $1.2 \pm 0.1$; ; and greater in $14 \mathrm{dCIDR} \mathrm{PGF}_{2 \alpha}$ compared with control on $\mathrm{d} 30(1.5 \pm 0.1$ vs.1.1 \pm 0.1$)$. The treatment by day interaction for class 2 follicles $(P<$ $0.05)$ seemed to be explained by fewer class 2 follicles in 14dCIDR-PGF ${ }_{2 \alpha}$ compared with control on d 14 (0.85 \pm 0.15 vs.1.18 \pm 0.15 ) and more class 2 follicles in 14dCIDR-PGF ${ }_{2 \alpha}$ compared with control on d 19 (2.82 \pm 0.26 vs. $2.04 \pm 0.26)$. The number of class 2 follicles was similar for treatments on d $30(2.02 \pm 0.18)$.

The percentage of heifers categorized as having different diameter LF was similar on d 0 [the majority of heifers had a CAT $2(10-14.9 \mathrm{~mm}) \mathrm{LF}$; Figure 3A]. The percentage of heifers with different category LF differed on d 14 (day of CIDR removal for 14 dCIDR-PGF $2 \alpha$ heifers; $P<0.01$; Figure 3B). A greater percentage of 14dCIDR-PGF $\mathrm{d}_{2 \alpha}$ heifers with CAT $3 \mathrm{LF}(P<0.01)$ and a lesser percentage of $14 \mathrm{dCIDR}^{\mathrm{P}} \mathrm{PF}_{2 \alpha}$ heifers with CAT 1 LF $(P<0.01)$ was observed on d 14 . On $d 19$ ( $5 \mathrm{~d}$ after CIDR removal for $14 \mathrm{dCIDR}-\mathrm{PGF}_{2 \alpha}$ heifers), fewer $(P<0.05)$ CAT $2 \mathrm{LF}$ heifers were noted in the $14 \mathrm{dCIDR}-\mathrm{PGF}_{2 \alpha}$ treatment and more $(P<0.001)$ CAT $1 \mathrm{LF}$ heifers in the $14 \mathrm{dCIDR}-\mathrm{PGF}_{2 \alpha}$ treatment compared with control (Figure 3C). An effect of treatment on LF category on d 30 was observed $(P<0.05$; Figure 3D). A tendency $(P<0.10)$ was seen for a greater percentage of CAT $2 \mathrm{LF}$ heifers in the $14 \mathrm{dCIDR}-\mathrm{PGF}{ }_{2 \alpha}$ treatment and a tendency $(P<0.10)$ for fewer CAT 1 LF heifers was seen in the $14 \mathrm{dCIDR}-\mathrm{PGF}_{2 \alpha}$ treatment compared with control.

CL, Ovarian Follicles, and Progesterone on d 44. Eight $14 \mathrm{dCIDR}-\mathrm{PGF}_{2 \alpha}$ and 19 control heifers were treated with a second $\mathrm{PGF}_{2 \alpha}$ injection on $\mathrm{d} 44$. No effect of treatment was observed on CL diameter (20.6 \pm $1.0 \mathrm{~mm}), \mathrm{LF}$ diameter $(13.3 \pm 0.5 \mathrm{~mm})$, SLF diameter $(9.0 \pm 0.6 \mathrm{~mm})$, or number of class $1(11.5 \pm 1.9)$, class $2(2.3 \pm 0.4)$, or class $3(1.5 \pm 0.2)$ follicles on $\mathrm{d} 44$. The percentage of heifers with CL in different categories (3.7, 0, 29.6, and $66.7 \%$ for CAT 1, 2, 3, and $4 \mathrm{CL}$, respectively) or LF in different categories $(7.4,70.4$, 22.2 and $0 \%$ for CAT $1,2,3$, and $4 \mathrm{LF}$, respectively) were also not affected by treatment.

\section{Estrus Response}

An effect of treatment was detected $(P<0.001)$ on the percentage of heifers that were observed in estrus on d 14, 15, 16, 17, 18, or 19 (day of and first $5 \mathrm{~d}$ after CIDR removal in $14 \mathrm{dCIDR}-\mathrm{PGF}_{2 \alpha}$ heifers; Figure $\left.4 \mathrm{~A}\right)$. As expected, a greater $(P<0.001)$ percentage of heifers were observed in estrus for 14dCIDR-PGF ${ }_{2 \alpha}(75.4 \%)$ compared with control (22.8\%). Most 14dCIDR-PGF ${ }_{2 \alpha}$ heifers were in estrus on d 2 after CIDR removal [Figure $4 \mathrm{~A}$; interval to estrus for $14 \mathrm{dCIDR}-\mathrm{PGF}_{2 \alpha}=2.1 \pm$ $0.1 \mathrm{~d}$ and not different from control $(2.3 \pm 0.2 \mathrm{~d})]$.

An effect of treatment was detected $(P<0.001)$ on estrus response after $\mathrm{PGF}_{2 \alpha}$ on d 30 . A greater percentage of heifers treated with 14dCIDR-PGF ${ }_{2 \alpha}(86.0 \%)$ were in estrus during the $5 \mathrm{~d}$ after $\mathrm{PGF}_{2 \alpha}$ compared with the control $(56.1 \%$; $P<0.001$; Figure 4B). Regardless of treatment, most heifers were in estrus on $\mathrm{d}$ 2 or 3 after $\mathrm{PGF}_{2 \alpha}$. The interval to estrus was similar for $14 \mathrm{dCIDR}-\mathrm{PGF}_{2 \alpha}$ and control $(2.4 \pm 0.2$ and $2.5 \pm$ $0.1 \mathrm{~d}$, respectively).

Forty-nine $14 \mathrm{dCIDR}-\mathrm{PGF}_{2 \alpha}$ heifers were inseminated during the $5 \mathrm{~d}$ after the first $\mathrm{PGF}_{2 \alpha}$ injection. Eight 14dCIDR-PGF $\mathrm{d}_{2 \alpha}$ heifers were treated with a second $\mathrm{PGF}_{2 \alpha}$ injection and $4(50 \%)$ were not detected in estrus and inseminated during the $5 \mathrm{~d}$ after the second 

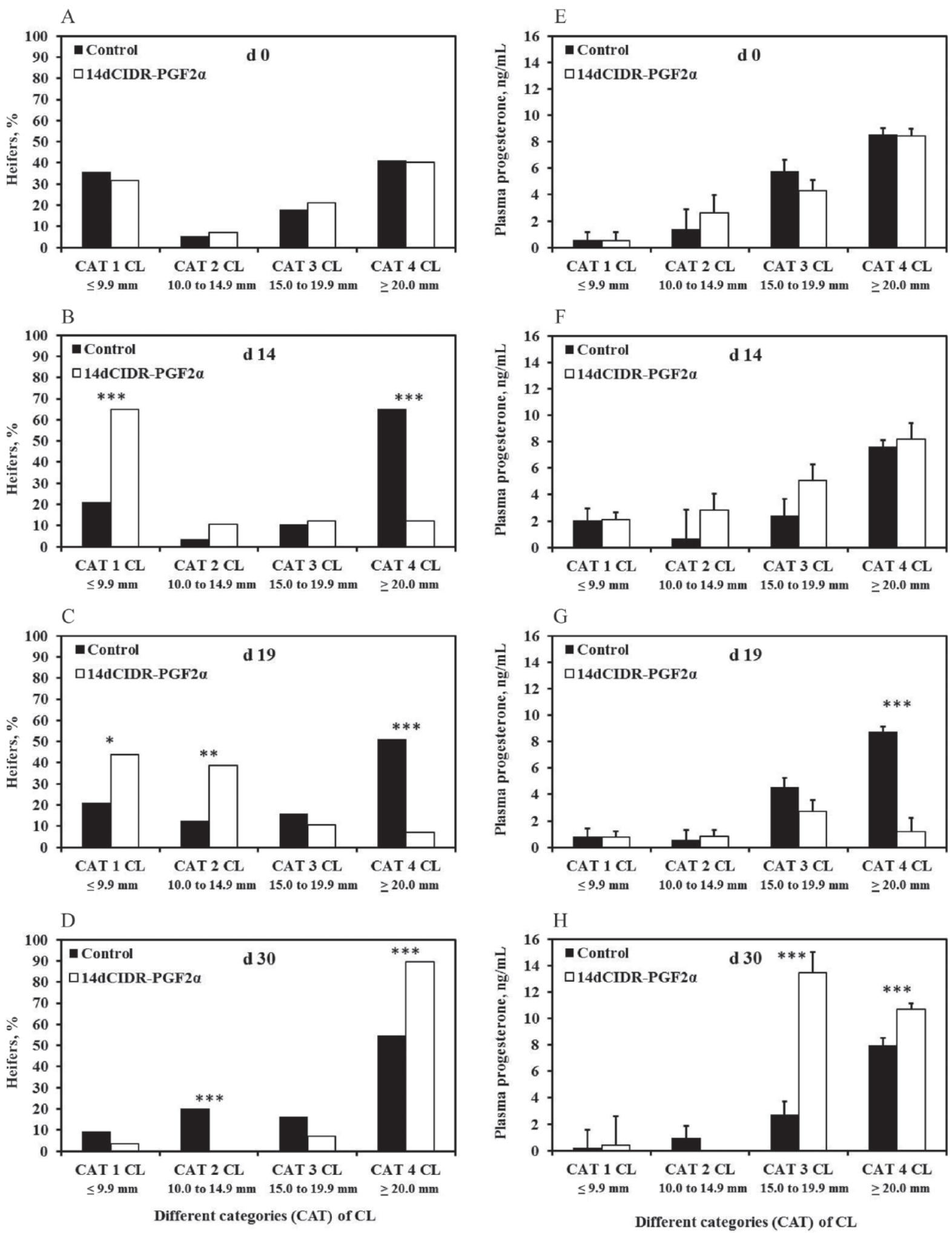

Figure 2. The percentage of heifers in each treatment [controlled internal drug release (CIDR) of progesterone for $14 \mathrm{~d}\left(14 \mathrm{dCIDR}-\mathrm{PGF}{ }_{2 \alpha}\right.$; $1.38 \mathrm{~g}$ of progesterone; Pfizer Animal Health, New York, NY) or control] possessing a corpus luteum (CL) within different categories (CAT) for diameter (CAT 1, $59.9 \mathrm{~mm}$; CAT 2, 10.0-14.9 mm; CAT 3, 15.0-19.9 mm; and CAT 4, $\geq 20 \mathrm{~mm}$ ) on d 0 (A), d 14 (B; removal of CIDR insert), d 19 (C; 5 d after CIDR removal), and d 30 (D; $\mathrm{PGF}_{2 \alpha}$ administration) and the concentrations of plasma progesterone in the same heifers of $\mathrm{d}$ $0,14,19$, and 30 (E, F, G, and H, respectively). Symbols above bars represent differences within each individual category $(* * * P<0.001$, $* * P$ $<0.01,{ }^{*} P<0.05$; Fisher's exact test). Categories without a symbol did not differ $(P>0.10)$ between treatments. 

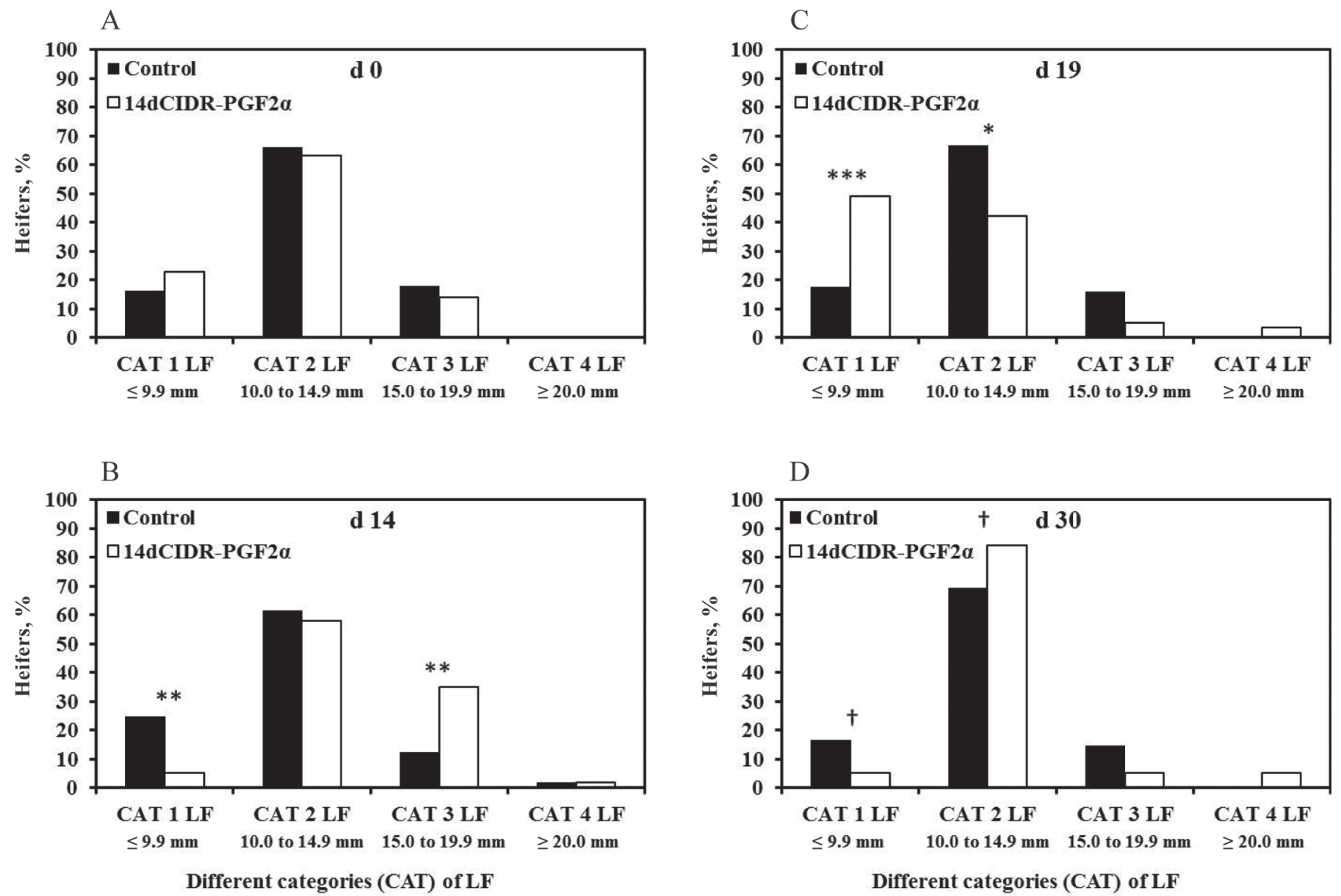

Figure 3. The percentage of heifers in each treatment [controlled internal drug release (CIDR) of progesterone for $14 \mathrm{~d}^{(14 \mathrm{dCIDR} \mathrm{PGF}}{ }_{2 \alpha}$; $1.38 \mathrm{~g}$ of progesterone; Pfizer Animal Health, New York, NY) or control] possessing a largest follicle (LF) within different categories (CAT) for diameter (CAT 1, $\leq 9.9 \mathrm{~mm}$; CAT 2, 10.0-14.9 mm; CAT 3, 15.0-19.9 mm; and CAT 4, $\geq 20 \mathrm{~mm}$ ) on d 0 (A), d 14 (B; removal of CIDR insert), d 19 (C; 5 d after CIDR removal), and d 30 (D; $\mathrm{PGF}_{2 \alpha}$ administration). Symbols above bars represent differences within each individual category $\left({ }^{* * *} P<0.001,{ }^{* *} P<0.01,{ }^{*} P<0.05, \dagger P<0.10\right)$. Categories without a symbol did not differ $(P>0.10)$ between treatments.

$\mathrm{PGF}_{2 \alpha}$ injection. Thirty-two control heifers were inseminated during the $5 \mathrm{~d}$ after the first $\mathrm{PGF}_{2 \alpha}$ injection. Six control heifers were inseminated after the initial 5-d period but before the second $\mathrm{PGF}_{2 \alpha}$ injection. Nineteen control heifers received a second $\mathrm{PGF}_{2 \alpha}$ injection. One control heifer $(5 \%)$ was not detected in estrus after the second $\mathrm{PGF}_{2 \alpha}$ injection. The percentage of heifers in estrus on a given day after the second $\mathrm{PGF}_{2 \alpha}$ injection was similar across treatments $(48 \%$ on $\mathrm{d} 2,22 \%$ on $\mathrm{d} 3$, $7 \%$ on $\mathrm{d} 4,4 \%$ on $\mathrm{d} 5$, and $19 \%$ not detected in estrus).

Data collected at the ovarian ultrasound on d 30 were examined relative to whether or not the heifers were detected in estrus on d 14 to 19 (day of and first $5 \mathrm{~d}$ after CIDR removal in $14 \mathrm{dCIDR}-\mathrm{PGF}_{2 \alpha}$ heifers) and whether or not the heifer was detected in estrus after $\mathrm{PGF}_{2 \alpha}$ on d 30 (Figure 5). An effect of detected estrus during d 14 through 19 on the percentage of heifers with CL in different categories was observed. Heifers detected in estrus between d 14 and 19 had a greater percentage of CAT 4 CL on d 30 compared with heifers not detected in estrus $(P<0.001$; Figure $5 \mathrm{~A})$. The percentage of heifers with different category LF on d 30 was not affected by the detection of estrus between $d$ 14 and 19 (Figure 5C). A greater percentage of heifers detected in estrus after $\mathrm{PGF}_{2 \alpha}$ had CAT $4 \mathrm{CL}(P<$ 0.001 ; Figure 5B) and CAT 2 LF $(P<0.01$; Figure 5D) on d 30 compared with heifers that were not detected in estrus after $\mathrm{PGF}_{2 \alpha}$.

\section{Conception Rate After Insemination}

A tendency for an effect of treatment $(P<0.10)$ on conception rate (no. pregnant/no. AI) was noted for heifers inseminated during $5 \mathrm{~d}$ after the first $\mathrm{PGF}_{2 \alpha}$ administration for $14 \mathrm{dCIDR}^{-\mathrm{PGF}_{2 \alpha}}(30 / 49,61.2 \%)$ compared with control $(13 / 32,40.6 \%)$. When all first 
A

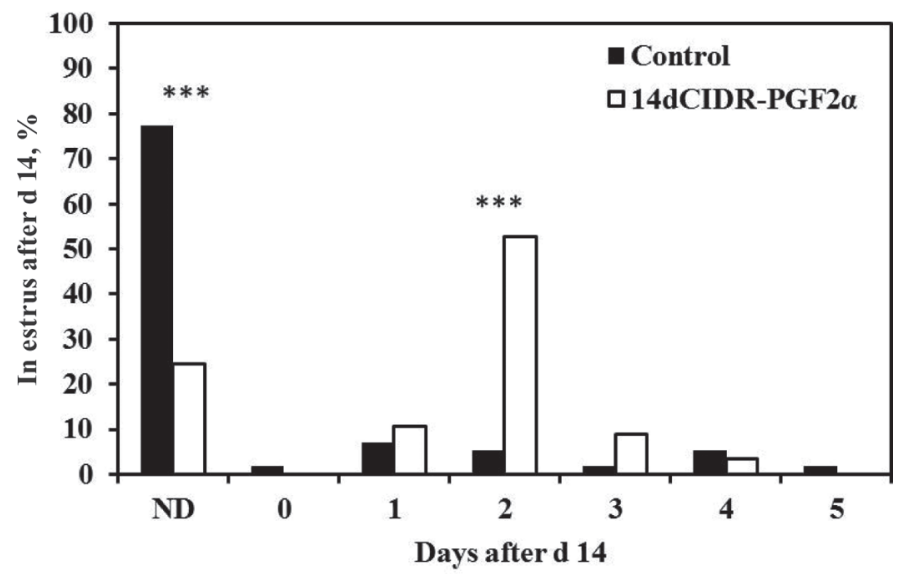

B

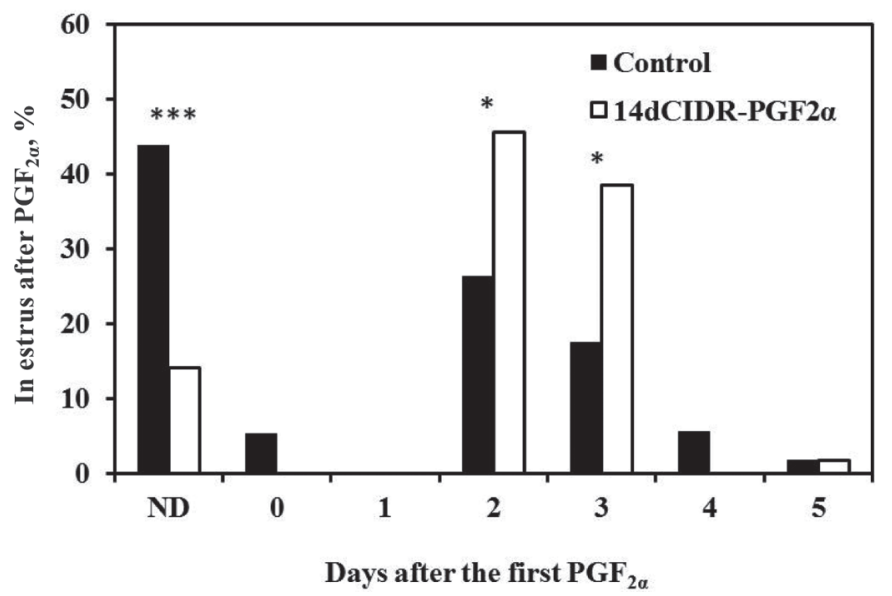

Figure 4. Percentage of heifers in estrus on specific days or that were not detected in estrus (not detected; ND) after d 14 [A; removal of controlled internal drug release (CIDR) insert in the heifers treated with a CIDR of progesterone for $14 \mathrm{~d}$ (14dCIDR-PGF $\mathrm{PG}_{2 \alpha} ; 1.38 \mathrm{~g}$ of progesterone; Pfizer Animal Health, New York, NY) and no treatment in the control heifers] or after $\mathrm{PGF}_{2 \alpha}(\mathrm{B})$ for heifers that were assigned to either $14 \mathrm{dCIDR}-\mathrm{PGF}_{2 \alpha}$ program or in the control. Symbols above bars represent differences within each individual day $(* * * P<0.001$, $\left.{ }^{*} P<0.05\right)$. Categories without a symbol did not differ $(P>0.10)$ between treatments.

inseminations were included (insemination after first, second, or third $\mathrm{PGF}_{2 \alpha}$ administration), no effect of treatment on conception rate was seen $(63 / 114,55.3 \%)$. A tendency for an effect of technician on first insemination conception rate was observed (technician 1, 63.3\%; technician 2, 46.3\%; $P<0.10$ ), but the treatment by technician interaction was not significant. Two heifers (one $14 \mathrm{dCIDR}-\mathrm{PGF}_{2 \alpha}$ and one control) were initially diagnosed as pregnant at the first pregnancy diagnosis (d 35 to 42 after AI) but later were diagnosed not pregnant at the second pregnancy diagnosis (d 56 to 63 after AI). No effect of treatment on second AI conception rate was noted $(23 / 53 ; 43.4 \%)$.

\section{Survival Analysis}

Survival curves for the proportion of heifers that were not inseminated during the first $30 \mathrm{~d}$ after the first $\mathrm{PGF}_{2 \alpha}$ injection were different $(P<0.05)$ for $14 \mathrm{dCIDR}-$ $\mathrm{PGF}_{2 \alpha}$ compared with control (Figure 6A). More heifers in the $14 \mathrm{dCIDR}-\mathrm{PGF}_{2 \alpha}$ group were inseminated during the first $17 \mathrm{~d}$ after the first $\mathrm{PGF}_{2 \alpha}$ injection. Survival curves for the proportion of heifers that were not pregnant during the first $30 \mathrm{~d}$ after the first $\mathrm{PGF}_{2 \alpha}$ injection also differed $(P<0.05)$ for $14 \mathrm{dCIDR}-\mathrm{PGF}_{2 \alpha}$ compared with control (Figure 6B). More heifers within the $14 \mathrm{dCIDR}-\mathrm{PGF}_{2 \alpha}$ treatment were pregnant during the first 3 wk after the $\mathrm{PGF}_{2 \alpha}$ injection.

\section{DISCUSSION}

We compared a $14 \mathrm{dCIDR}-\mathrm{PGF}_{2 \alpha}$ program with a control program that employed $\mathrm{PGF}_{2 \alpha}$ alone for the synchronization of estrus in dairy heifers. The $14 \mathrm{dCIDR}-\mathrm{PGF}_{2 \alpha}$ program has been used previously in beef heifers and beef cows (Schafer et al., 2007; Leitman et al., 2009), and a recent report demonstrated its utility in dairy heifers (Mallory et al., 2013). We used a single $\mathrm{PGF}_{2 \alpha}$ injection as a control so that we could specifically examine what effect the $14 \mathrm{~d}$ of progesterone exposure via the CIDR insert treatment had on the CL and population of follicles at the time of the $\mathrm{PGF}_{2 \alpha}$ injection (16 $\mathrm{d}$ after CIDR insert removal in $14 \mathrm{dCIDR}-\mathrm{PGF}_{2 \alpha}$ treated heifers and at an essentially random stage of the cycle in control heifers). We found that the 14-d progesterone exposure via CIDR insert treatment resulted in $>95 \%$ of heifers with large (CAT 3 and CAT 4), functional (based on plasma progesterone) CL at the time of $\mathrm{PGF}_{2 \alpha}$ injection (d 30; Figures $2 \mathrm{D}$ and $2 \mathrm{H}$ ). At the same time, nearly $85 \%$ of the heifers had CAT 2 LF (10.0 to $14.9 \mathrm{~mm}$; Figure 3D). The large percentage of heifers with large, functional CL and also a moderately-sized LF may help explain why the $14 \mathrm{dCIDR}-\mathrm{PGF}_{2 \alpha}$ program has demonstrated excellent fertility when timed $\mathrm{AI}$ is used after the $\mathrm{PGF}_{2 \alpha}$ injection (Mallory et al., 2013).

The purpose of the $14 \mathrm{~d}$ of progesterone exposure via the CIDR insert treatment is to synchronize estrus and ovulation. The estrus and ovulation after the progesterone exposure lead to the formation of a CL that is then regressed by using an injection of $\mathrm{PGF}_{2 \alpha}(16 \mathrm{~d}$ after CIDR removal). A large percentage of heifers will be in the latter half of the luteal phase when the $\mathrm{PGF}_{2 \alpha}$ is administered16 d after CIDR removal. Heifers that are late in the luteal phase when $\mathrm{PGF}_{2 \alpha}$ is administered are ideal because the CL is the most responsive to $\mathrm{PGF}_{2 \alpha}$ at that time (Xu et al., 1997). The $\mathrm{PGF}_{2 \alpha}$ administration synchronizes a fertile estrus. The heifers can be 

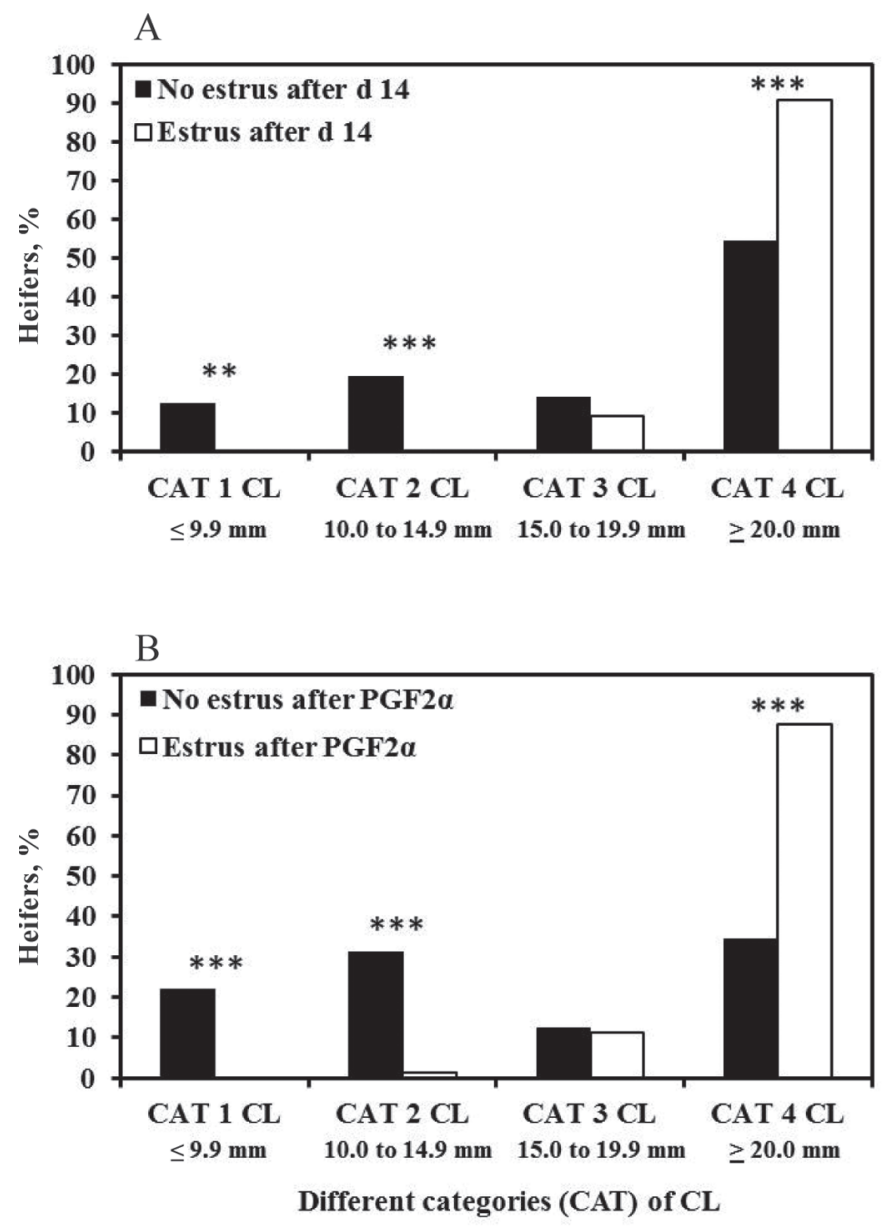
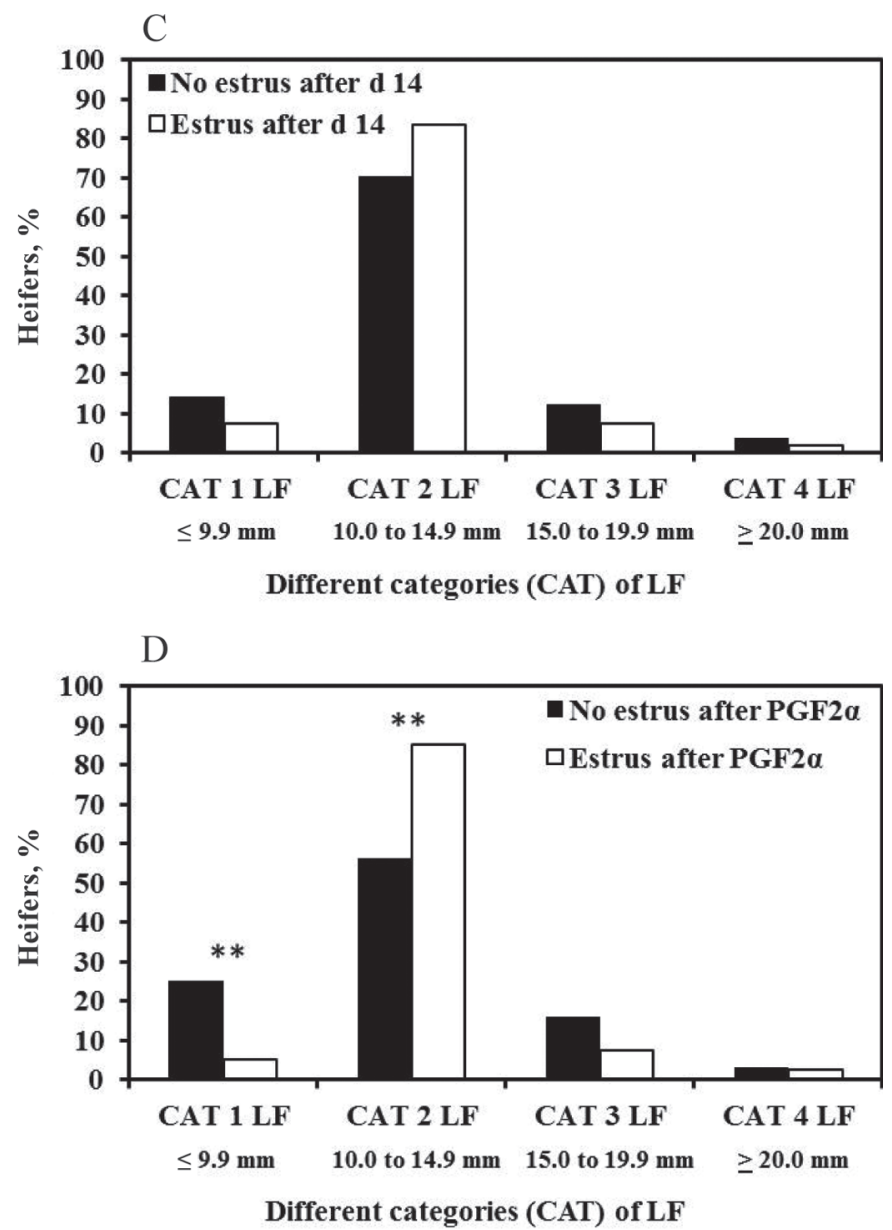

Figure 5. The percentage of heifers possessing a corpus luteum (CL) or largest follicle (LF) within different categories (CAT) for diameter

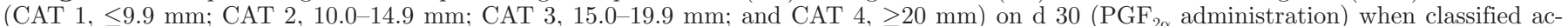
cording to whether they were observed in estrus during the $5 \mathrm{~d}$ after $\mathrm{d} 14$ (A and $\mathrm{C}$ ) or whether they were observed in estrus after the PGF ${ }_{2 \alpha}$ administration (B and D). Symbols above bars represent differences within each individual category $(* * * P<0.001, * * P<0.01 ;$ Fisher's exact test). Categories without a symbol did not differ $(P>0.10)$ between treatments.

inseminated after observed estrus (as performed in this study) or be subjected to a timed AI $66 \mathrm{~h}$ after $\mathrm{PGF}_{2 \alpha}$ injection (Mallory et al., 2013).

On $\mathrm{d}$ 0, the $14 \mathrm{dCIDR}-\mathrm{PGF}_{2 \alpha}$ and control heifers were similar in terms of ovarian morphology and plasma progesterone concentrations (Figures 2A, 2E, and 3A). On d 14 (day of CIDR removal), however, heifers in the $14 \mathrm{dCIDR}-\mathrm{PGF}_{2 \alpha}$ and control treatments differed in terms of the diameter of their CL and the size of the ovarian follicles. A larger percentage of 14dCIDR$\mathrm{PGF}_{2 \alpha}$ heifers had CAT $1 \mathrm{CL}(\leq 9.9 \mathrm{~mm}$ diameter; Figure 2B) and CAT 3 follicles (15.0 to $19.9 \mathrm{~mm}$ diameter; Figure 3B) compared with control. The presence of the small CL and large follicles is indicative of a persistent follicle where the progesterone from the CIDR insert prevented ovulation in heifers that had undergone luteal regression. Removal of the CIDR led to estrus in approximately $2 \mathrm{~d}$ (Figure 4A), an interval to estrus that is consistent with other CIDR studies (Lucy et al., 2001). Despite the induction of a persistent follicular state, the heifers did not seem to develop ovarian cysts ( $\geq 25 \mathrm{~mm}$; Hamilton et al., 1995; Roche et al., 1999) and few CAT $4(\geq 20 \mathrm{~mm})$ LF were observed (Figure 3B).

Heifers were examined on d 19 ( 5 d after CIDR removal in the $14 \mathrm{dCIDR}-\mathrm{PGF}_{2 \alpha}$ heifers) so that ovulation and subsequent CL formation could be assessed. As expected, the $14 \mathrm{dCIDR}-\mathrm{PGF}_{2 \alpha}$ and control heifers differed on d 19 (the control heifers were untreated at this time). The percentage of $14 \mathrm{dCIDR}-\mathrm{PGF}_{2 \alpha}$ heifers with CAT $2 \mathrm{LF}$ (10.0 to $14.9 \mathrm{~mm}$ ) were lesser than control on d 19 (Figure 3C) and a corresponding increase in CAT $1 \mathrm{LF}(\leq 9.9 \mathrm{~mm})$, an increase in the number of class 2 (6 to $9 \mathrm{~mm}$ ) follicles, and an increase in the percentage of heifers with CAT 2 CL (10.0 to $14.9 \mathrm{~mm}$; Figure $2 \mathrm{C}$ ) were observed for $14 \mathrm{dCIDR}-\mathrm{PGF}_{2 \alpha}$ com- 
A

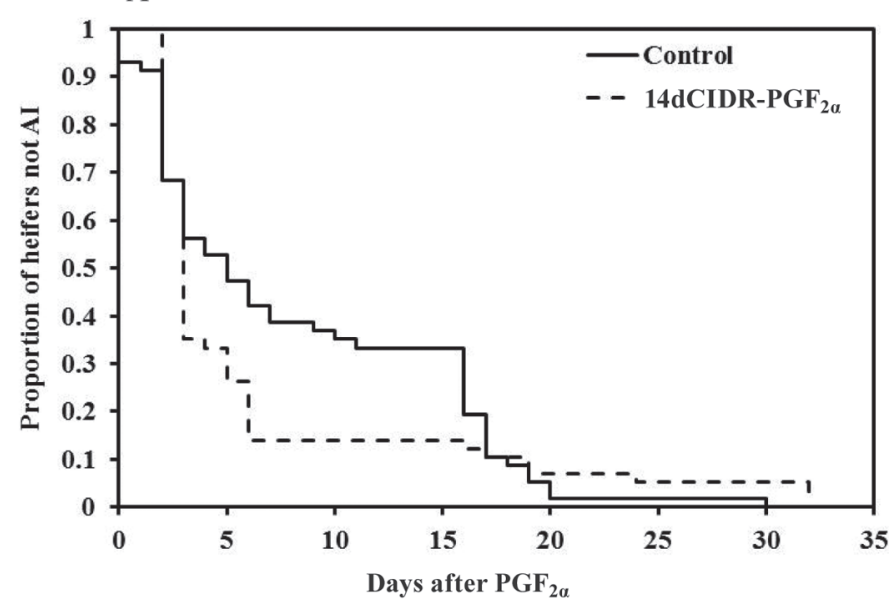

B

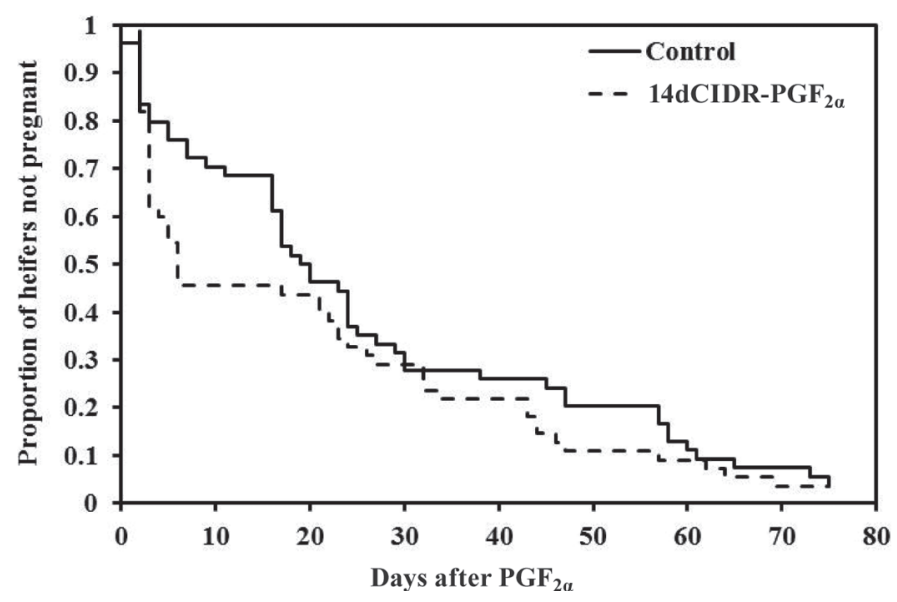

Figure 6. Survival analysis for the proportion of heifers within each treatment [controlled internal drug release (CIDR) of progesterone for $14 \mathrm{~d}\left(14 \mathrm{dCIDR}-\mathrm{PGF}_{2 \alpha} ; 1.38 \mathrm{~g}\right.$ of progesterone; Pfizer Animal Health, New York, NY) or control] that were not inseminated (A) or not pregnant $(\mathrm{B})$ on each day after $\mathrm{PGF}_{2 \alpha}$ administration. Survival curves differed $(P<0.05)$ for the first $30 \mathrm{~d}$ after $\mathrm{PGF}_{2 \alpha}$ administration.

pared with control. The increase in CAT $1 \mathrm{LF}$, CAT $2 \mathrm{CL}$, and class 2 follicles for $14 \mathrm{dCIDR}-\mathrm{PGF}_{2 \alpha}$ heifers compared with control was theoretically caused by ovulation after CIDR removal. Presumably, the CAT 2 CL is the newly formed CL and the greater number of class 2 follicles represents the synchronized initiation of the first follicular wave. The CAT $1 \mathrm{LF}$ is the first wave dominant follicle (Lucy et al., 1992). Although some of the $14 \mathrm{dCIDR}-\mathrm{PGF} \mathrm{F}_{2 \alpha}$ heifers possessed CAT $4 \mathrm{CL}$ on d 19 (Figure 2C), it was interesting to find that the CL were essentially nonfunctional based on circulating progesterone concentrations (Figure $2 \mathrm{G}$ ). The diameter of a CL at $5 \mathrm{~d}$ after CIDR removal, therefore, may not be a useful method to determine CL function (progesterone secretion) because loss of function but not morphological regression of the CL can occur in some heifers at that time.

On d 30 (day of $\mathrm{PGF}_{2 \alpha}$ injection), clear differences were noted for the $14 \mathrm{dCIDR}-\mathrm{PGF}_{2 \alpha}$ heifers compared with control. Over $95 \%$ of the 14dCIDR-PGF ${ }_{2 \alpha}$ heifers had either CAT 3 or CAT 4 CL (Figure 2D) and the CL were functional based on plasma progesterone concentrations (Figure $2 \mathrm{H}$ ). In addition to large and functional CL, nearly $85 \%$ of the 14 dCIDR-PGF ${ }_{2 \alpha}$ heifers had CAT 2 LF (10.0 to $14.9 \mathrm{~mm}$; Figure 3D). We also observed larger SLF and more class $3(\geq 10 \mathrm{~mm})$ follicles in the $14 \mathrm{dCIDR}-\mathrm{PGF}_{2 \alpha}$ heifers on $\mathrm{d} 30$. We believe that these additional large follicles are explained by the presence of an atretic first wave dominant follicle and a healthy second wave dominant follicle at the time of $\mathrm{PGF}_{2 \alpha}$ (approximately d 14 of the estrous cycle for $14 \mathrm{dCIDR}-\mathrm{PGF}_{2 \alpha}$ heifers). When treatments were combined (14dCIDR-PGF $2 \alpha$ and control), $100 \%$ of heifers observed in estrus from d 14 to 19 (i.e., during the 5 $\mathrm{d}$ after CIDR removal) had CAT 3 or CAT 4 CL when $\mathrm{PGF}_{2 \alpha}$ was administered on d 30 (Figure 5A). Likewise, when both treatments were combined, $99 \%$ of heifers observed in estrus after $\mathrm{PGF}_{2 \alpha}$ on d 30 had CAT 3 or CAT 4 CL when the $\mathrm{PGF}_{2 \alpha}$ was administered (Figure 5B). The importance of a preceding estrus for establishing a known stage of the estrous cycle for $\mathrm{PGF}_{2 \alpha}$ administration and improving overall estrual response was clearly demonstrated.

This study was not designed to compare conception rate after insemination. Nonetheless, it was worth noting the excellent conception rate after first $\mathrm{PGF}_{2 \alpha}$ and $\mathrm{AI}$ in the $14 \mathrm{dCIDR}-\mathrm{PGF}_{2 \alpha}$ heifers $(61.2 \%)$ compared with control $(40.6 \%)$. These conception rates were achieved despite the fact that sexed semen was used, which generally has been shown to have lesser fertility compared with conventional semen (DeJarnette et al., 2009). An important question that should be examined in future studies is whether the $14 \mathrm{dCIDR}^{-} \mathrm{PGF}_{2 \alpha}$ program has an advantage in terms of fertility when compared with other programs. The $14 \mathrm{dCIDR}^{-} \mathrm{PGF}_{2 \alpha}$ program groups a large percentage of heifers in the latter half of the luteal phase when the greatest concentrations of blood progesterone are typically observed (Figure $2 \mathrm{H}$ ). Previous work has demonstrated the beneficial effect of progesterone before breeding on subsequent fertility (Pursley and Martins, 2011). Whether the 14dCIDR- PGF $2 \alpha$ program confers a fertility advantage via a mechanism that involves prebreeding progesterone remains to be elucidated.

A criticism of our study design is that the 14dCIDR$\mathrm{PGF}_{2 \alpha}$ program was compared with a less-than-optimal control program that involved a single $\mathrm{PGF}_{2 \alpha}$ injection. A single $\mathrm{PGF}_{2 \alpha}$ injection was used to allow examination of the effect of progesterone via the CIDR treatment on 
the response to $\mathrm{PGF}_{2 \alpha}$. An alternative control would be 2 injections of $\mathrm{PGF}_{2 \alpha}$ at an 11 to 14-d interval with insemination after the second $\mathrm{PGF}_{2 \alpha}$ injection (Lauderdale, 2009). The aforementioned program increases the estrual response by ensuring that a large percentage of heifers with CL are available when the second $\mathrm{PGF}_{2 \alpha}$ is administered. In the present study, heifers that were inseminated after the first $\mathrm{PGF}_{2 \alpha}$ were not treated $14 \mathrm{~d}$ later with a second $\mathrm{PGF}_{2 \alpha}$ injection (d 44). The program that we used, therefore, was not entirely identical to the 11 to 14 -d program mentioned earlier in this paragraph because we inseminated heifers after the first injection and retreated heifers that were not detected in estrus. In future studies, it will be necessary to test the $14 \mathrm{dCIDR}-\mathrm{PGF}_{2 \alpha}$ program against alternative programs that involve a series of $\mathrm{PGF}_{2 \alpha}$ injections. These future studies should be designed to assess the ovarian response (diameter of ovulatory follicle and CL) as well as fertility for the 2 programs.

\section{CONCLUSIONS}

Treating dairy heifers with a CIDR for $14 \mathrm{~d}$ was an effective method to synchronize the subsequent estrous cycle and the development of ovarian structures (CL and follicles). At $16 \mathrm{~d}$ after CIDR removal, a large percentage of heifers had large, functional CL and large follicles (10.0-14.9 mm). Treatment with $\mathrm{PGF}_{2 \alpha}$ led to a large percentage of heifers in estrus within 2 to 3 d. The uniform ovarian and endocrine response to the combined treatment of a 14-d progesterone exposure via CIDR insert with $\mathrm{PGF}_{2 \alpha} 16 \mathrm{~d}$ after insert removal provides a promising foundation for further investigation into the effectiveness of the $14 \mathrm{dCIDR}^{-} \mathrm{PGF}_{2 \alpha}$ program for either AI after estrus or timed AI in dairy heifers.

\section{REFERENCES}

Ahmad, N., F. N. Schrick, R. L. Butcher, and E. K. Inskeep. 1995. Effect of persistent follicles on early embryonic losses in beef cattle. Biol. Reprod. 52:1129-1135.

Anderson, L. H., C. M. McDowell, and M. L. Day. 1996. Progestininduced puberty and secretion of luteinizing hormone in heifers. Biol. Reprod. 54:1025-1031.

DeJarnette, J. M., R. L. Nebel, and C. E. Marshall. 2009. Evaluating the success of sex-sorted semen in US dairy herds from on farm records. Theriogenology 71:49-58.
Hamilton, S. A., H. A. Garverick, D. H. Keisler, Z. Z. Xu, K. Loos, R. S. Youngquist, and B. E. Salfen. 1995. Characterization of ovarian follicular cysts and associated endocrine profiles in dairy cows. Biol. Reprod. 53:890-898.

Kirby, C. J., M. F. Smith, D. H. Keisler, and M. C. Lucy. 1997. Follicular function in lactating dairy cows treated with sustained-release bovine somatotropin. J. Dairy Sci. 80:273-285.

Lauderdale, J. W. 2009. ASAS centennial paper: Contributions in the Journal of Animal Science to the development of protocols for breeding management of cattle through synchronization of estrus and ovulation. J. Anim. Sci. 87:801-812.

Leitman, N. R., D. C. Busch, D. A. Mallory, D. J. Wilson, M. R. Ellersieck, M. F. Smith, and D. J. Patterson. 2009. Comparison of long-term CIDR-based protocols to synchronize estrus in beef heifers. Anim. Reprod. Sci. 114:345-355.

Louis, T. M., H. D. Hafs, and B. E. Seguin. 1973. Progesterone, LH, estrus and ovulation after prostaglandin $F_{2 \alpha}$. Exp. Biol. Med. 143:152-155.

Lucy, M. C., H. J. Billings, W. R. Butler, L. R. Ehnis, M. J. Fields, D. J. Kesler, J. E. Kinder, R. C. Mattos, R. E. Short, W. W. Thatcher, R. P. Wettemann, J. V. Yelich, and H. D. Hafs. 2001. Efficacy of an intravaginal progesterone insert and an injection of $\mathrm{PGF}_{2 \alpha}$ for synchronizing estrus and shortening the interval to pregnancy in postpartum beef cows, peripubertal beef heifers, and dairy heifers. J. Anim. Sci. 79:982-995.

Lucy, M. C., J. D. Savio, L. Badinga, R. L. De La Sota, and W. W. Thatcher. 1992. Factors that affect ovarian follicular dynamics in cattle. J. Anim. Sci. 70:3615-3626.

Mallory, D. A., S. L. Lock, D. C. Woods, S. E. Poock, and D. J. Patterson. 2013. Hot topic: Comparison of sex-sorted and conventional semen within a fixed-time artificial insemination protocol designed for dairy heifers. J. Dairy Sci. 96:854-856.

National Research Council. 2001. Nutrient Requirements of Dairy Cattle. 7th rev. ed. Nat. Acad. Sci., Washington, DC.

Odde, K. G. 1990. A review of synchronization of estrus in postpartum cattle. J. Anim. Sci. 68:817-830.

Patterson, D. J., G. H. Kiracofe, J. S. Stevenson, and L. R. Corah. 1989. Control of the bovine estrous cycle with melengestrol acetate (MGA): A review. J. Anim. Sci. 67:1895-1906.

Pursley, J. R., and J. P. Martins. 2011. Impact of circulating concentrations of progesterone and antral age of the ovulatory follicle on fertility of high-producing lactating dairy cows. Reprod. Fertil. Dev. 24:267-271.

Revah, I., and W. R. Butler. 1996. Prolonged dominance of follicles and reduced viability of bovine oocytes. J. Reprod. Fertil. 106:39-47.

Roche, J. F., E. J. Austin, M. Ryan, M. O'Rourke, M. Mihm, and M. G. Diskin. 1999. Regulation of follicle waves to maximize fertility in cattle. J. Reprod. Fertil. Suppl. 54:61-71.

Schafer, D. J., J. F. Bader, J. P. Meyer, J. K. Haden, M. R. Ellersieck, M. C. Lucy, M. F. Smith, and D. J. Patterson. 2007. Comparison of progestin-based protocols to synchronize estrus and ovulation before fixed-timed artificial insemination in postpartum beef cows. J. Anim. Sci. 85:1940-1945.

Xu, Z. Z., L. J. Burton, and K. L. Macmillan. 1997. Reproductive performance of lactating dairy cows following estrus synchronization regimens with $\mathrm{PGF}_{2 \alpha}$ and progesterone. Theriogenology 47:687-701. 